\title{
Chapter 5 \\ An Emerging Dragon: Vietnamese Education After Resolution 29
}

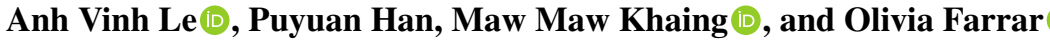

\begin{abstract}
In the years since its independence in 1975, Vietnam has experienced much political, social, economic, and educational change. Multiple comprehensive reforms over the past few decades have served to transform Vietnam from a country of war into an "emerging dragon" across all social and economic sectors, including education. In 2013, Vietnam passed one of the most significant pieces of education legislature in the country's history: Resolution 29, a fundamental and comprehensive education reform that put the development of Vietnam's education system at the top of socioeconomic development plans. This chapter accounts for the major changes of Vietnam education system after Resolution 29, including the country's "success formula" as well as its lapses. It makes further recommendations for educational policymakers and educators in Vietnam regarding the role of the education sector in the coming ever-disruptive social and economic context.
\end{abstract}

\subsection{Introduction}

The developmental progress of Vietnam has evolved from an education system struggling with the long, brutalizing post-war conflicts to one that made the headlines in worldwide newspapers for leading other countries in international academic contests and assessments. In its first attempt to participate in the Program for International

\footnotetext{
A. V. Le $(\bowtie) \cdot$ P. Han

Vietnam Institute of Educational Sciences, 101 Tran Hung Dao, Hanoi, Vietnam

e-mail: vinhla@vnies.edu.vn

P. Han

e-mail: puyuanhan@gse.harvard.edu

M. M. Khaing

New School Yangon Network I Harvard Graduate School of Education, 10 Yadanar Mon 6th

Street, Hlaing Township, Yangon, Myanmar

e-mail: mawmawkhaing@newschoolyangon.org

O. Farrar

Harvard College I Oxford University, 45 Kurt Rd, Pittsford, NY 14534, USA
}

(C) The Author(s) 2022

F. M. Reimers et al. (eds.), Education to Build Back Better,

https://doi.org/10.1007/978-3-030-93951-9_5 
Student Assessment (PISA) in 2012, Vietnamese youths topped those from OECD countries, ranking 17th in mathematics, 8 th in science, and 19th in reading out of 65 participating nations. Three years later, in the 2015 PISA, the average score of Vietnam was 32 points above the OECD average (while staying in top 10 worldwide in science) - equivalent to about one full year of schooling. Overall, given its top position in the PISA average score ranking and international academic competitions, Vietnam represents an impressive success story for the effects of efficient investment in education (Kataoka et al., 2020).

On November 4th, 2013, Vietnam passed one of the most significant pieces of education legislature in the country's history: Resolution 29, a fundamental and comprehensive reform of the education system. Resolution 29 was guided by the principle that investments in education result in long-term investments in economic development, and thus put Vietnam's education system at the top of socioeconomic development plans. Beginning in 2013, national and local governments unrolled a series of reforms based around a small number of linked key policy levers: targeted investment, a changed curriculum and pedagogy, and a focus on teacher quality.

This chapter provides an analysis of the reform implementation through Fernando Reimers' five perspectives of educational changes (Reimers, 2020), as well as its outcomes and challenges.

The analysis utilizes both quantitative and qualitative data, including several primary sources directly obtained from the Vietnamese government. Our interpretation of the stated goals and objectives of Resolution 29 derives largely from the official document. We have also summarized data derived from the reports of international organizations (including UNESCO and the World Bank), and academic papers about the results of Resolution 29. The most recent 2020 Vietnam Education Sector Analysis report (MOET, 2020) has informed the bulk of our findings regarding statistical measures of educational attainment and performance in Vietnam since Resolution 29 , as it is the most current and comprehensive review of the relevant data.

To supplement our analysis of these papers and findings, we conducted interviews with five leading officials from the Vietnamese education system, including Director/Vice Director Generals of several departments from Ministry of Education and Training and formal Director General of Vietnam Insitute of Educational Sciences. Although we had access to a great deal of information, the lack of quanitative data for ethnic minorities and students with special needs was inevitable. Interviews with senior managers in the education system will help us to fill in this missing information. Besides, these interviews provide invaluable reflections on the implementation and effectiveness of Resolution 29 and inform future directions for educational policy in Vietnam. 


\subsection{Country Context}

To fully understand the impact of Resolution 29, it is first necessary to contextualize our discussion within the political, geographic, demographic, social, macroeconomic, and labor market environments which have affected the Vietnamese education sector over the last two decades. These factors, while external to the immediate education system, shape the development of education demand and supply.

Historically, Vietnam has gone through five waves of education reform in the last several decades. In the first wave, which lasted roughly from 1945 to 1954, Vietnamese education reforms were framed around fighting poverty and illiteracy. Before the country's liberation in 1945, the educational system was under French colonial control, and only 5\% of the population was literate (MOET, 2020). The second wave of reform took place during the Vietnam War, when the country was temporarily divided; the main objectives during this period of conflict were to expand the school network and to establish modern universities (Duggan, 2001). Following the end of the war in 1975, the third major educational reform focused on curriculum unification between the North and the South of the country (MOET, 2020). The literacy rate rose to $84 \%$ by 1980 , and rates continued to increase throughout the 1980 s as the government approved new textbooks for all grades over the country through an intensive anti-illiteracy campaign (MOET, 2020).

Until the mid-1990s, Vietnam's national education system was divided into a four-tiered system. This system consisted of (1) pre-school education; (2) general education; (3) vocational education; and (4) higher education (Duggan, 2001). This system was highly fragmented and has since been revised to enable significant growth in general secondary education. Primary schools and lower secondary schools were combined, and these systems have now become separate. Despite many improvements to the education system during this period, severe funding shortages constrained the size and quality of the education system. The fourth wave of reform began in 1986, with the passage of the major national reform 'Doi Moi,' a major national reform that switched the country's economy from a centrally planned system to socialist-oriented market. The biggest achievement in this period was the general expansion of universal education; within the first nine years of the reform, general education grew to $98 \%$ enrollment for primary schools and $84 \%$ for lower secondary schools (MOET, 2020). Higher education also witnessed a period of growth, with the number of postsecondary students tripling from 1998 to 2011 (Duggan, 2001).

Politically, Vietnam is a socialist country. Central legislative authority rests with the National Assembly of the Socialist Republic of Vietnam, and executive authority rests with line ministries and agencies. At the local level, each tier of government has People's Councils and People's Committees for the conduct of provincial legislative and executive authority. The implementation of Resolution 29 was significant in terms of unifying the objectives of Vietnam's central governing body, the National Assembly. Fundamental and comprehensive changes in education often require changes in political viewpoints, and require coordination between ideas and people, stakeholders and resources, politics and political implementation. Since educational 
change impacts all levels of society, reform also often results in changes in political leadership and/or administration. As stated in the Resolution 29, "Education is the top priority, the cause of the Communist Party, the Government and the people." Despite this stated emphasis, the Resolution also acknowledged the government's shortfalls in reaching its stated mission.

Indeed, the Resolution attributed weaknesses in the existing educational system to political and administrative shortfalls. The Resolution emphasized that strengthening political leadership goes hand in hand with effective policy execution and called for stronger involvement of the Communist Party in the education system. Politically, the reform represented a unifying force between government and society, connecting the aims of education with both the State and the people.

The current economic climate in Vietnam is robust, and favorable for sustained investment in education. Since the Doi Moi era in the 1980s, strict commitment to macroeconomic stability and extensive market reforms have helped the country to achieve rapid and inclusive economic growth (IMF, 2017). To facilitate modernization, there has been a labor market shift towards high-skilled jobs. As we will see, Resolution 29 sought to expand economic investment in Vietnam's education system and to suggest policies for training the labor force. In the lead-up to Resolution 29, education was reprioritized as essential for both social and economic development and as a vehicle for supporting Doi Moi.

Geographically, the size and shape of Vietnam has had a substantial impact on its demographics. The population is unevenly distributed from one region and province to another, with the greatest number of people living in the cities. Urbanization is on the rise, primarily fueled by migrations in the population cohorts of students and working age individuals, who move to the cities in search of education and job opportunities in more dynamic economic zones. The average annual population growth rate in urban areas from 2009 to 2019 was $2.6 \%$ per year, over twice as high as the average annual national population growth rate, and nearly six times higher than what was observed in rural areas (MOET, 2020). These disparities in population density across the country have a direct impact on school organization and related operating costs (MOET, 2020).

Furthermore, migration trends in the country are currently balanced by population shifts, including a demographic transition and declining population. From 2009 to 2019 , the percentage of total population within the 15-65 age-group declined by $1.1 \%$, accounting for $68.0 \%$ of the total population. Based on the same 2019 data, the proportion of the population under 15 years old and 60 years and older represented $24.3 \%$ and $7.7 \%$, respectively (MOET, 2020). While these relative cohort sizes create a demographic window of opportunity for the country (one working age person for half a dependent) it also results in a 'thinned' population pyramid at the lower tiersmeaning that, alongside increased life expectancy rates and lower fertility rates, the country will have a large aging population to care for in the future. While a shrinking population eases the overall pressure on the education system and allows Vietnam to benefit from a positive demographic dividend in the immediate context, the shift presents major challenges for the future. 
Socially, Vietnam has experienced significant improvements in key social indicators over the last decade, creating a particularity conducive environment for educational demand. However, stark regional, ethnic, and socio-economic disparities prevail, ultimately affecting schooling systems. Rates of poverty in the country dropped precipitously from the period of 2002-2018, falling from over 70\% to less than 6\% (MOET, 2020). Literacy rates have been on the rise, with the most recent censuses indicating that around $96 \%$ of all Vietnamese people aged 15 and over can read and write (MOET, 2020). Vietnam has also made remarkable achievements in health care and disease prevention, especially for children; this is reflected by infant and maternal mortality rates, which have rapidly decreased in the last two decades (MOET, 2020). These markers of increased quality of living have created a fertile environment for the Vietnamese education system.

\subsection{The Reform}

We can identify five major problems when assessing the Vietnamese education system before 2013. This analysis is based largely around internal reports obtained from the Vietnam Ministry of Education and Training.

The first problem is that Vietnamese education is still heavy in theory, and there is a lack of practice. This is true across grades and subjects, in which teachers and students focused more on rote learning rather than actual understanding. In addition, highstake exams have led to teaching and learning that revolves almost entirely around exams, rather than imparting skills and lifestyle ethics to students. The concept of "comprehensive education" has not translated into school practice. Ineffective career-guidance programs have also led to a high dropout rate in high schools.

The second problem conerns equity. Vietnam has done a great job in improving equality in education but there are still many things that remain to be done. Vietnam has achieved the goal of universal primary education since 2000 and universalization of lower secondary education since 2010. There is no gender inequality in access to basic education (primary and lower secondary education department). Enrollment rates for ethnic minority students and children with special needs were quite good at the primary level but fell sharply at the secondary levels. In provinces with difficult conditions, the percentage of students continuing to study after lower secondary school is very low, affecting the quality of local human resources.

The third problem is that Vietnam's education system is fragmented and poorly connected. The lack of linkage between levels and levels of education makes it difficult to separate flows. Formal education and continuing education are also disconnected. The national qualification framework between training levels has not yet been established.

The fourth problem is the outdated teaching and assessment methods. Teaching and learning methods are mainly on transmission of knowledge, which cannot promote initiative and creativity in teachers and learners. The existing forms of assessment only focus on results and knowledge, rather than assessing the 
progress and capacity of learners. Students are participating in plenty of summative assessments but not so much on formative feedback.

The fifth problem is the administrative mechanism of education. Provisions on decentralization between central and local levels are not clear. Educational institutions, especially higher education institutions, do not have appropriate mechanisms for autonomy.

The final issue is the lack of quality teachers and administrators. In recent decades, the supply of teaching staff in Vietnam has been insufficient in both quantity and quality to keep pace with the demand of institutions and students. Given the size of the sector in 2012, it was estimated that the system had a shortfall of ten thousand teachers. Besides, the quality of teachers and administrators also shows signs of decline. For a long time, teacher education did not attract good students. The cut-off for entering universties of education are relatively low, leading to poor quality new teachers. Quality was an even greater issue within high education facilities, with less than $20 \%$ holding a doctorate in the same year.

The shortage in quantity and quality of teaching staff can be explained by the consistently low income in the education sector. Even though the largest share of government expenditure on education is put towards staff compensation-which is common in the education sector, where teachers make the biggest percentage of state officials and are prioritized by the Government in terms of welfare and benefitsthe average monthly salary of educators in Vietnam were not competitive when considered against workers from other sectors.

Given the transitional context of the Vietnamese economy within worldwide movements towards globalization, another comprehensive reform was pivotal to the country's socioeconomic development. Thus, a theory of action for the 2013 educational reform addresses these five problems, building off weaknesses to create opportunity. The fundamental and comprehensive education reform in Vietnam thus creates an environment for positive change in Vietnam generally, equipping the young generations with the tools to advance socio-economic development into the future.

\subsubsection{Key Solutions}

Broadly, Resolution 29 proposed eight key solutions to address the challenges affecting the Vietnamese education system: (i) Enhancing innovation in education management; (ii) Promoting teachers and education managers' development; (iii) Innovating content and teaching methods, examination, testing and education assessment; (iv) Increasing investment of resources and renewing education finance distribution mechanism; (v) Strengthening the linkage between universities and the labor market as well as scientific research and technology transfer to meet societal needs; (vi) Fostering educational development for disadvantaged areas, ethnic minorities and social policy beneficiaries; (vii) Promoting education science; and (viii) Expanding and improving the effectiveness of international cooperation in education. 


\subsubsection{Enhancing Innovation in Education Management}

Resolution 29 implemented several key reforms in state and educational management. Some of the main policies included administrative decentralization, especially by allowing local educational agencies to participate in deciding the personnel, finance, and administration of institutions of preschool education, compulsory education, and vocational education.

\subsubsection{Promoting Teachers and Education Managers' Development}

To keep pace with the demand of institutions and students, Resolution 29 determinedthat the teaching force should be increased at all levels, and teacher professional development should be emphasized. Since most teachers in Vietnam were undertrained to practice the changes in curriculum, pedagogical methods, and testing that were put in place with the educational overhaul of Resolution 29, Vietnam has developed various teacher training programs via in-site training courses as well as online platforms (WB, 2016).

\subsubsection{Innovating Content and Teaching methods, Examination, Testing and Education Assessment}

Resolution 29 made important statements regarding the purpose of education, especially in terms of aligning Vietnam with twenty-first century goals. The reform emphasized the importance of educational innovation at all levels, from system down to individual. It addressed social and emotional learning (SEL), soft skills, and civic learning, and promoted policies to develop "personality, ethics, lifestyle, law, and citizen's awareness." Social and emotional learning is an integral part of effective schooling at all levels and has become a cornerstone of educational reform worldwide in the last decade. Resolution 29 recognized and emphasized the importance of SEL, attempting to orient education towards valuing learners' capacity and personal qualities. Cultural learning was stressed in the reform, especially in terms of aligning educational goals with fundamental cultural values (including Marxism and the ideology of Ho Chi Minh) and traditional customs and morality. Provisions for physical education, civic education (national defense and security), and practical education (career advice and financial knowledge) were also reaffirmed.

Resolution 29 prioritized revamping educational assessments at all levels of education. Some of the policies included within this general reform effort included: (1) Reducing pressure for exams in secondary schools, especially those designed for admission to vocational schools and universities; (2) Improving the assessment methods associated with vocational education institutions, including by enabling employers to participate in the evaluation of training; (3) Changing the structure and content of university admission examinations, especially by combining 
entrance exams with school records and incorporating measurements of SEL, technical skills, and organizational abilities within admission papers; (4) Using international programs of assessment to help gauge the success of the education system, from the level of the country as a whole down to each locality.

\subsubsection{Increasing Investment of Resources and Renewing Education Finance Distribution Mechanism}

In many parts of the country, especially impoverished and rural areas, schools were under-resourced. Resolution 29 emphasized the importance of improving resourcing and increasing government expenditure in education across all levels. For preschools and compulsory secondary education, the State committed to raising investments in the development of public educational institutions and encouraging the development of non-public schools to satisfy demands.

The Resolution called to increase funding for higher education and vocational training as well, setting targets for investment based on economic-technical norms and quality standards of education services. Beyond increasing government expenditures, the Resolution called for intensifying private sector educational involvement, especially for vocational education and higher education. By increasing economic competition in education, all learners, employers, and educational institutions would be held to higher standards.

\subsubsection{Strengthening the Linkage Between Universities and the Labor Market as Well as Scientific Research and Technology Transfer to Meet Societal Needs}

Since the Doi Moi era beginning in 1986, Vietnam has experienced rapid and inclusive economic growth (IMF, 2017). To maintain this growth, Resolution 29 emphasized the importance of keeping education in step with economic development. As such, the reform instituted policies to connect education with labor market demands. Some of these policies included rearranging and connecting the network of vocational and higher education institutions, choosing uniform standards for training levels and qualifications, and orienting institutions of higher education towards scientific and technical research, application and practice.

\subsubsection{Fostering Educational Development for Disadvantaged Areas, Ethnic Minorities and Social Policy Beneficiaries}

In large part due to the geography and demographics of the country, educational disparities along socioeconomic, ethnic, and regional lines persist in Vietnam. Ethnic minorities, children living in underdeveloped areas, poor families, families 
with many children, and families whose parents have a background of lower educational attainment tend to be more vulnerable or at risk to fall into the educational wayside. Children from disadvantaged at heightened risk of not being ready for primary school than their better-off peers, and often do not have the same resources to succeed once within the system. Resolution 29 sought to address these educational inequities by promoting investment, expanding educational access, and developing specific policies for the vulnerable groups.

\subsubsection{Promoting Education Research}

To help Vietnam meet the demands of modernization and industrialization, Resolution 29 emphasized the importance of promoting research into educational best practices. The reform implemented policies to raise the quality and effectiveness of scientific and technical research on education, especially in the context of pedagogy and administration. On the budgetary side, these policies centered on increasing investment for institutions of higher education, combining training and research, connecting institutions with businesses, and prioritizing the development of laboratories/technological centers/experimental facilities. To encourage the development of attitudes conducive to a scientifically minded society and education system, Resolution 29 suggested introducing "policies [that] encourage students to do scientific research.

\subsubsection{Expanding and Improving the Effectiveness of International Cooperation in Education}

International cooperation in education is becoming increasingly important and prevalent in today's globalized world. In recognition of this, Resolution 29 implemented policies to help Vietnam exchange best practices with other nations, and to connect the Vietnamese education system with the resources of an interconnected world. Among these policies, Resolution 29 provided for more government-funded overseas training in the sciences and in research, encouraging the increased use of foreign training institutions for higher education and vocational education.

\subsubsection{Major Goals}

Beyond these eight major policy directions, the Resolution also targeted specific aspects of reform at each level of the education system.

For preschool education, the major goals of the reform were to help children develop their physical, mental, and emotional health, and to prepare children for the early demands of primary education. The reform also set several benchmarks, 
including universal completion of primary education for all five-year-old children by 2015, exempting all tuition fees by 2020, and standardizing the system of preschools.

For secondary education, Resolution 29 emphasized SEL and healthy physical habits, the formation of personality and civil capability, and early career advice. The Resolution also looked towards improving social and cultural education in secondary schools, with an increased focus on teaching ideals, traditions, ethics, lifestyles, foreign languages, information technology, practical skills and ability to apply knowledge to life. In terms of concrete benchmarks, the Resolution set several interconnected goals: ensuring that all enrolled students graduated from junior high schools by 2015 , the quality of secondary education was raised and made compulsory (for at least 9 years) by 2020, and that $80 \%$ of adolescents over 18 years of age completed secondary education or equivalent by 2020 . Finally, the reform emphasized that all high school curricula incorporate some aspect of vocational guidance, to help prepare students for careers post-graduation.

For vocational education, the reform not only focused on developing a more skilled labor force, but also emphasized "Cultivating the gifted, and developing learners' personal qualities, creativity, and ability of self-learning Furthermore, it sought to expand the network of occupational and vocational schooling within institutions of higher learning, and to diversify technology and training for all professions. Finally, in terms of continuing education, Resolution 29 made an explicit effort to increase educational opportunity across all demographics and regions of the country - especially for those in rural and low SES areas, and for the beneficiaries of incentive policies. The reform emphasized the importance of lifelong learning and helping older cohorts to develop knowledge via continued education (in all forms) and improve professional skills and life quality. These goals were held as essential to enable workers to change career paths, and to ensure continued national and regional economic development.

\subsection{Implementation Analysis}

In this section, we will analyze the implementation of Resolution 29 to identify the strengths and weaknesses of education policies in the post-resolution period of Resolution, through the lens of Professor Fernando Reimers' Five Perspectives: Cultural, Psychological, Institutional, Political, and Professional (Reimers, 2020).

\subsubsection{Cultural Perspective}

The educational approach through a cultural perspective will be realized by comparing educational goals with social needs, focusing on the role of education in socioeconomic development, as well as expectations of how schooling fits into larger societal contexts (Reimers, 2020). Vietnamese society has a tradition of 
attaching importance to learning. Vietnam has always been appreciated for creating a positive learning environment, ensuring school discipline, and helping students have good learning attitudes. The participation and encouragement of young people from parents and students are also positive factors in forming a learning society (WB, 2020). Besides, Vietnamese society always has high expectations for education. Although Vietnam's education has made achievements that are highly appreciated by the international community, comments on the level of people's satisfaction with education on the mass media are still not commensurate. With such cultural characteristics, Resolution 29 has received the attention and support of the entire society.

From another angle, education in Vietnam is still very heavy on exams and academic achievement. As it stands, entrance exams for transfer classes, entrance exams for selective schools, and university entrance exams are reported to be quite stressful. In general education, the race and competition take place right from the moment children prepare for Grade 1. Throughout subsequent levels of education, the competition only becomes fiercer, often requiring auditions among candidates and schools. Consequently, students are overloaded with academic assignments and filled with pressure (Hoang, 2018). For such reasons, in the system of very comprehensive solutions for Resolution 29, assessment reform is chosen as the breakthrough solution. This solution is expected to be the trigger to solve the bottlenecks of the system (CCCP, 2013). However, the innovation of exams and assessment also faces many challenges when it directly affects the interests of many people.

As a result of these intense pressures to achieve, there is considerable dishonesty rooted in the education sector. The phenomenon of cheating in the high school for higher grades in graduation exams is cause for societal worry and frustration. Innovations in testing methods and technology application have helped detect largescale score fraud in 2017. With the determination of the Ministry of Education and Training and authorities, many educational administrators in some localities were disciplined and some were criminally convicted. However, we did witness that the exams in the following years were held stably and transparently, regaining trust from the society and people (MOET, 2020).

\subsubsection{Psychological Perspective}

We now look at education through a psychological perspective and attempt to evaluate student learning using science (Reimers, 2020). Vietnam has performed well in increasing access to education through universal education at the primary and lower secondary levels. The quality of education is also praised from the perspective of international assessments and international science Olympiad results (Kataoka et al., 2020). However, there are concerns about how teaching and learning at schools in Vietnam tend to convey knowledge through rote learning. Students are said to be taught to memorize knowledge, instead of being shown how to apply knowledge. It 
has been stated that Vietnam Education is very good on paper, but good exam results alone will not prepare pupils for the next industrial revolution (Reed, 2018).

These issues have been clearly identified by Resolution 29, which aims to educate Vietnamese people with characteristics and competencies that match Vietnam's rapid development (CCCP, 2013). An important component of the innovation is to build a new general education curriculum, moving from a knowledge-based curriculum to a competency-based curriculum. The process of building a new curriculum has been implemented since 2016. By the end of 2018, the Ministry of Education and Training has officially issued a new general education curriculum that fundamentally changes the approach from "according to content" towards "developing characteristics and competencies". The new curriculum is also well-built based on the application of educational science, ensuring vertical connectivity between the levels in the same subject, horizontal connection between subjects in the same class level, and is aligned to the physiological development of learners.

Another point to note in this reform is that the new policy "one curriculummany textbooks" is applied for the first time. For the past 45 years, Vietnam has pursued the policy of a unified national textbook. This approach helps to ensure the background quality of the education system, but also perpetuates some inadequacies; specifically, teaching and learning remain too attached to textbook materials, rather than encouraging new knowledge or skill acquisition. The new policy is implemented with two goals. The first is to encourage teaching and learning in schools without textbooks, thereby unleashing the creativity of teachers and students in teaching. The second is to prompt schools and localities to actively build practical teaching plans which are suitable to their own needs and expectations (Le, 2020).

Although the curriculum was officially applied in the 2020-2021 school year, the elements of educational methodology, teaching, and assessment have been partially applied at all levels, bringing impacts to teaching and learning in general education (Nguyen et al, 2020).

\subsubsection{Institutional Perspective}

An institutional perspective requires identifying the norms, structures, organizations, and elements of the system that can enhance education (Reimers, 2020). Determining of the role of existing institutions is an important step in the implementation of Resolution 29. The Ministry of Education and Training is the key player in reform implementation, alongside all relevant departments. Because the scope of Resolution 29 is very wide, with many large projects implemented synchronously, it also reflects limitations in the management capacity of the relevant departments. For example, work of the Renovating General Education Project (GREP) funded by World Bank has been postponed for nearly 2 years, with many tasks cancelled due to limited capacity of the Project Management Board (Duong, 2020). 
Considering these limitations, a very strong decentralization mechanism is essential for ensuring consistency in implementation. The provincial Department of Education and Training has a very significant role to play in ensuring the success of the reform equitably. It should be noted that many levers are decentralized to localitiesincluding the management of teacher and the allocation of resources for educationto ensure that the conditions for implementation are met. For example, in primary education, the new general education school requires that all elementary schools offer 2 sessions per day. This direction is suitable to meet the real needs of families. However, only about $65 \%$ of localities can meet the conditions for teaching 2 sessions per day. The remaining localities should have a reasonable budget allocation plan to meet the minimum conditions soon (IMF, 2017).

Pedagogical universities also play important roles in curriculum development, teacher training, and preparation. Pedagogical universities are beneficiaries of the Enhancing Teacher Education Project (ETEP). The ETEP project is sponsored by World Bank, with a total investment of up to 100 million USD and the aim of strengthening capacity for 8 pedagogical universities in point (ETEP, 2019).

The commitment to coordinate a range of key stakeholders from central to local in education and related disciplines demonstrates a strength of the Ministry of Educational and Training. However, further studies also suggest that this perspective was challenged because of the limited capabilities of enforcement agencies, as well as the ability to effectively connect between different agencies, even within the Ministry of Education and Training. This restriction will present a major challenge to the long-term goals of the reform.

\subsubsection{Political Perspective}

The political perspective describes how various groups' interests must be addressed and considered in the development and implementation of reform (Reimers, 2020). Comprehensive reform through Resolution 29 comes from the highest level, the Central Committee of the Communist Party of Vietnam, followed by Resolution 88 of the National Assembly of Vietnam on innovation. programs and textbooks. In many cases, however, political interests will have strong effects on the implementation of reform and may override the educational interests of students and parents (Reimers, 2020). This is unavoidable and must be carefully analyzed to minimize conflicts of interest during implementation.

Further analyzing the implementation of the "one curriculum-many textbooks" policy, we can clearly see the difficulties in this perspective. This policy affects the textbook industry, which has been monopolized for more than 50 years in Vietnam. After the curriculum was approved in late 2018, the competition between textbook publishers increased. The original plan was that the RGEP Project would undertake the construction of an official set of textbooks for the Ministry of Education and Training, and publishers would build other series of textbooks to expand the choices for students. However, there are conflicting opinions regarding this implementation. 
On one hand, there are many concerns that the Ministry of Education and Training should not be related to the compilation of the textbooks. This work should be left entirely to the publishers. This approach will create a fair game among publishers. On the other hand, there are also many concerns about the need for an official set of textbooks disseminated by the Ministry of Education and Training. In the early years of implementing the new policy, this is a safe solution to ensure the quality of textbooks that prevents reliance on commercial publishers. In the media, lawmakers are constantly putting pressure on the cancellation of the "one curriculum-many textbooks" policy. These pressures have significantly affected the implementation process, as the RGEP project failed to fulfill its initial mission of building an official textbook set (Ha, 2020).

Despite many such difficulties, the process of reforming curricula and textbooks has had initial successes. By the end of 2019, the Minister of Education and Training has approved 5 sets of Grade 1 textbooks, with a total of 46 books in 9 subjects and educational activities allowing use in the school year 2020-2021. The selection of textbooks is implemented openly and transparently by localities (MOET, 2020).

\subsubsection{Professional Perspective}

The professional perspective assesses how well teachers and administrators prepare for innovation, in terms of both conceptual and procedural knowledge.

In 2018, the Ministry of Education and Training issued professional standards for teachers and principals of schools and lecturers at pedagogical universities, to improve the quality of the workforce in the education sector. The Enhancing Teacher Education Project has built 9 training modules for teachers at each grade level (elementary, middle, high school) to develop professional competencies, to meet the professional standards of teachers and to meet the requirements of the new general curriculum (DTA, 2019).

With respect to qualification standards, most teachers and educational administrators at all educational levels have met the standard or higher (the percentage of teachers meeting the standard and above standard for kindergarten is $96.6,99.0 \%$ for teachers at junior high schools, $99.6 \%$ for teachers of high schools, and $82.7 \%$ for university faculty) (MOET, 2020). This is an important basis for the Ministry of Education and Training in proposing raising training qualifications for teachers in the new Education Law 2019.

From an interview with Associate Professor Nguyen Xuan Thanh, Director General of Secondary Education Department, for the Ministry of Education and Training, we can see that the biggest obstacle that teachers must overcome in reforming the education system is psychological in nature-after all, the core information teachers impart remains basically unchanged, and while teachers have been instructed in new pedagogical methods they still lack specific knowledge and skills that are subject specific, that provide appropriate pedagogical competencies within each subject, and allow them to implement instructional tasks and 
approaches to assess students' knowledge. These should be the focus of professional learning communities for teachers in the coming period. The Director General of Secondary Education also mentioned that the "MOET will also be issuing guidance on professional learning communities and renovating teaching methods and assessment according to the competency-based approach. Our purpose is to raise the quality of professional learning communities at schools, particularly innovative teaching and assessment methods, as well as helping school leaders and teachers to actively select and develop topics and materials, taking the competency-based approach."

\subsection{Reform Outcomes}

In the last seven years since the implementation of Resolution 29, Vietnam's education has seen many encouraging results. The results can be categorized in terms of the eight main policy thrusts mentioned earlier.

\subsubsection{Enhancing Innovation in Education Management}

Since the 2013 reform, the Education Ministry of Vietnam has implemented several additional reform laws, which are outlined in the 2020 report Evaluation of implementation of the 2011-2020 education development strategy (VNIES, 2020) Since one of the major thrusts of this chapter is exploring the impact of the Resolution 29 , noting these recent amendments is necessary for us to mark the changes in the Vietnamese education system.

The National Assembly promulgated the Education Law (amended) in 2019 and the Higher Education Law (amending and supplementing several articles) in 2018. The Prime Minister issued the National Education System towards openness, continuity and lifelong learning. The Prime Minister promulgated the National Qualification Framework to ensure the equivalence of training levels and qualifications. However, the system of legal normative documents on education is not consistent. There are still contradictions and overlaps between sub-law documents (VNIES, 2020).

McAleavy, Ha, and Fitzpatrick identified a policy delivery challenge in Vietnam education system. Primary schools and lower secondary schools are supported and monitored by a district-level Bureau of Education and Training, whereas government high schools are supervised in a similar way by a provincial-level Department of Education and Training. Education department officials are expected to explain policy to schools and provide both support and monitoring to ensure fidelity of implementation. According to the regulations, the process is simultaneously both 'top down' and 'bottom up.' Under the circumstances, management in schools becomes rigid, inflexible, and inactive (McAleavy et al., 2018). 
In a recent policy note (WB, 2020), the World Bank also offered an in-depth analysis and assessment of Vietnam's higher education system, thereby giving recommendations on policies to promote higher education system governance. They stated that the higher education system in Vietnam is highly fragmented across many dimensions, including: (1) Vietnam does not have a single body responsible for the entire tertiary education and research system, (2) the existence of several hundred public research institutes operating independently from the universities, (3) multiple bylaws issued in recent years are seen as contributing to the complexity, fragmentation and inconsistencies of the regulatory framework, (4) the role played by MOET in initiating reforms and setting the long-term vision is undermined by inadequate capacity, resources and information, (5) no unified higher education information management system (HEMIS), which hinders evidence-based decision-making from all stakeholders.

\subsubsection{Promoting Teacher Professional Development}

At the time of Resolution 29, most teachers in Vietnam were undertrained to practice the changes in curriculum, pedagogical methods, testing, and management put in place with the educational overhaul. In the hopes of addressing these issues, Vietnam has developed various teacher training programs via in-site training courses as well as online platforms (WB, 2016). However, after the first semester of implementation, there are still many shortcomings. Currently, teachers do not fully understand the innovation objectives and are not given preparation time (VNIES, 2021). To that end, we believe that the ideology around teacher training needs to be restructured.

As it stands, the MOET has enacted professional standards for teachers, school principals, and lecturers at pedagogical universities. MOET also proposed raising training qualifications for teachers in the new Education Law 2019. Specifically, primary school teachers will have to have a four-year university degree instead of a three-year degree as before (VNIES, 2020).

Some elements of teacher professional development have been successful because of Resolution 29, however. Teacher conditions remain quite favorable, with relatively low pupil to teacher ratios (PTRs) and class sizes that are lower than set standards, especially compared with OECD averages (MOET, 2020). National averages hide regional and provincial disparities. Teacher shortages are not evenly distributed across the country, with some shortages affecting disadvantaged regions more than other regions. Teacher shortage is particularly striking in primary schools offering 2 sessions a day and in upper secondary schools. There is also evidence that teachers are in short supply in kindergartens (MOET, 2020). As reported in an interview with Dr. Nguyen Thi Mai Hoa, Permanent Member of Assembly's Committee for Culture, Education Youth, Adolescents and Children, there have been substantial efforts in Vietnam to promote the guidance, implementation, and preparation of teacher professional development policies by the Ministry of Education and Training. 


\subsubsection{Innovating Content and Teaching Methods, Examination, Testing and Education Assessment}

Major milestones during this period of education include the approval of a new competency-based curriculum, supported by The World Bank Group and launched in 2016. The curriculum was officially approved in 2018, and will be officially implemented from 2020 (MOET, 2018b). This new national curriculum aims to alter the outdated teaching and learning methods-which were formerly structured around the transmission of knowledge and memorization of facts-with technology-based education to equip students with hands on skills necessary for the twenty-first century. Compulsory subjects were reduced and complemented with optional and integrated subjects and theme activities (CPTC, 2018).

This is also the first time that Vietnam allowed the application of the policy of "one curriculum-many textbooks." However, the implementation in the first year met many difficulties. From the fact that teachers have not been fully trained, leading to incorrect understanding of the role of textbooks in the new program. After only 8 weeks, one of the textbooks was rejected by the public, and later discontinued. Content aside, the main cause identified was the inability of teachers to respond to reforms (VNIES, 2021).

Assessment reform at primary level is considered a highlight in the period 20132020. The MOET issued Circular 30 in 2014 and Circular 22 in 2016, which guide schools and teachers in innovating the assessment of students. Instead of evaluating the students based on the results, the comprehensive assessment aims to encourage and motivate students. The participatory assessment process is not meant to be compared to other students, but rather focuses on the progress in each student's performance. When launched in 2014, the process has been challenged due to concerns about the feasibility by public opinion, schools, and teachers. However, after two years of implementation, there have been obvious changes in primary education. The guiding principles of learning and teaching at primary schools now are what the students learned and what they could do, rather than their grades (VNIES, 2017).

The high school graduation examination and the university entrance examinations have also been radically renovated in the period of 2013-2020. To begin, the high school graduation examination and the university entrance examination have been combined, to become the national high school examination. The examination is held locally, to reduce, the burden of candidates who must travel to major cities to take university exams, thus reducing financial pressure on parents and society generally (Nguyen et al., 2020). 


\subsubsection{Increasing Investment of Resources and Renewing Education Finance Distribution Mechanism}

One of the key elements of achievement in the Vietnamese education sector is the consistently high expenditure on education, and the focus on primary and basic literacy education to ensure universalization, which specifically benefits the less advantaged regions. Such investment has yielded positive outcomes, with the overall rate of return to schooling in Vietnam surpassing those of most nearby countries (Thanh et al., 2018).

The share of total public expenditure in the education sector has always been among the largest of social and economic sectors for Vietnam; the country also ranks high among East Asia countries, with top sharing of public expenditure on education, approximately equal to Malaysia's. Meanwhile, the figures for Singapore and The Philippines are about 2.5-3\%, under 4\% for Indonesia, Hong Kong and Japan, and 4.5-5\% for Thailand and South Korea. It is worth noting, however, that these figures refer to the public expenditure as proportion of GDP only, and the total amount of education investment in Vietnam remains relatively low (Kataoka et al., 2020).

In recent years, the Vietnamese government's investment on education has been increasing, maintaining around $20 \%$ of total budget expenditures (GSO, 2016, 2017). However, the government expenditure on education, usually high at governmental central level, proved to be ineffective when spending autonomy was granted to local authorities. This is the result of the decentralization movement, whereby much of the responsibility of education decision making is shifted to provincial level authorities. In the recent higher education policy note by World Bank (WB, 2020), as of 2013, $64 \%$ of total expenditure on education was distributed by local government, whose spending priorities vary substantially across the country. This figure was not improved much in recent years (Viet et al., 2020).

\subsubsection{Promoting Science, Technology and Innovation Performance}

Despite remarkable progress in the quantity of research output, Vietnam remains at the bottom of benchmarking country list in the recent policy note by World Bank (WB, 2020). In terms of quantity, the number of citable documents per one million inhabitants of Vietnam is higher than that of the Philippines, but lower than that of Indonesia, Malaysia, and Singapore. In terms of quality and impact, Vietnam ranks bottom in the list.

Measures of technology transfer indicate that the contribution of Vietnam's universities to the national innovation system is also very low, at 1.24 patents per million of population, lower than that of Philippines (1.35), Thailand (3.16) and less than even $1 \%$ of China (233). On innovation capacity, Vietnam ranked 45th among 126 countries in 2018. This is an improvement of Vietnam from the rank of 64th in 2008. 
According to World Bank report on Science, Technology and Innovation in Vietnam, this low performance is identified because of inadequate and inefficient financing, insufficient research talent, limited links to the global research frontier, low level university-industry linkage, and under-developed research/ICT infrastructure (WB, 2019).

\subsubsection{Fostering Educational Development for Disadvantaged Areas, Ethnic Minorities and Social Policy Beneficiaries}

To ensure equal access to educational opportunities, promoting universalization of general education matters. Vietnam achieved universal primary education in 2000 and universal lower secondary education in 2010. One of the greatest achievements of Vietnam's education over the past five years is the universalization of preschool education for all 5-year-old children. As of 2017, profound effects on the development of preschool education have been documented. Comparing to 2010, the school's retention rate has expanded rapidly, with the enrollment rates of 5-year-old children rising by $13 \%$ to reach $99.96 \%$ in 2017 (MOET, 2018a).

Vietnam has made impressive strides regarding gender equity in education. While participation rates by female students have always been approximate to male counterparts at all study levels, over the past few years, researchers have found a reverse gender gap in enrollment and attainment rates, particularly regarding upper secondary level completion rates. However, there are still disparities in the quality of education between students in different target groups, especially, for students of ethnical minorities and students with disabilities (Vinh, 2019).

Improving educational access for ethnic minority children is the first policy priority, to be implemented by strengthening current government initiatives. One major leverage point is improving high-quality early-childhood education programs, especially by assigning teaching assistants proficient in the local mother languages in the beginning years of primary school to help facilitate the transition for children who do not speak Vietnamese at home. Another major factor is providing financial support-including cash transfer programs to households, subject to school attendance-to encourage children to attend upper secondary school. The enrollment numbers of ethnic minority students decreased dramatically from primary to tertiary level. These low educational attainment rates towards higher levels of study also seemed to be more potent for some specific groups of ethnic minorities (Dang \& Glewwe, 2018).

Despite efforts to support students with disabilities, the outcomes have not been improved, because of lower enrollment population at higher education. According to statistics from 2016 to 2017 by UNICEF and GSO, only $1 \%$ children with disabilities are in a special school/classroom (UNICEF \& GSO, 2018). The percentage of schools with suitable infrastructure and sanitation facilities for students with disabilities are 
$2.9 \%$ and $9.9 \%$, respectively. Even though a quarter of children with disabilities aged 2-17 live in poor households with schooling opportunity of $21 \%$ lower than those without disabilities, only $55.5 \%$ benefit from tuition fee reduction or exemption.

\subsubsection{Promoting Educational Research}

Moving forward, the question Vietnamese policy makers and educators must ask themselves should be how to prepare learners for a fast-changing context and required skills sets. An education environment that favors innovation and creativity, particularly focusing on the role of lifelong learning and sustainable development of learners, is fundamental. The evolution of such a system must be based on research-informed policies, particularly research in the field of educational sciences. According to a bibliometric analysis from Clarivate Web of Science database between 1991 and 2018 (Hoang et al., 2019), even though academic research output in education is rather underdeveloped, we can still observe an upward pattern over the last ten years, which signifies a fertile prospect for education in the country moving forward.

The Government has assigned the Ministry of Education and Training to lead the national research program on educational science in the 2016-2020 period. According to reports, 49 national tasks have been identified to support the implementation of the objectives of Resolution 29. These assignments have made an important contribution to a wide range of legal normative tasks. According to the report of the Office of Educational Science National Program (ESNP, 2020), dozens of monograph book and hundreds of scientific articles have been published, and hundreds of conferences and seminars have been held. The program is expected to continue implementing phase 2 from 2021 to 2025.

\subsubsection{Expanding International Cooperation in Education}

International cooperation in education has been strongly promoted in the period 2013-2020. The number of overseas students has steadily increased, about 8-10\% annually. The number of foreign students in Vietnam also doubled during this period, from 11,000 international students in 2013 to 21,000 international students in 2018. The number of Agreement scholarships awarded by Governments of other countries to Vietnamese students has also nearly doubled, from 862 scholarships granted in 2013 to 1446 scholarships granted in 2019 (Ly \& Marginson, 2019).

The size of affiliate programs is also constantly expanding, with about 35,000 people studying each year. The number of foreign-invested educational institutions has expanded, from only two foreign-invested universities to five universities in 2017. To date, there are 29 high schools with foreign investment. FDI projects in education are stable in terms of total investment. However, ODA and non-refundable aid to education have decreased in recent years as Vietnam has entered the group of 
low middle-income countries. Accreditation of affiliate programs, or foreign educational institutions, remains difficult. There is not much cooperation on credit recognition and conversion with regional and international countries. Therefore, there are still many shortcomings surrounding the recognition of diplomas (DIC, 2019).

\subsection{Challenges}

This chapter focused on three components in designing the future of teaching and learning from Resolution 29 onwards: pedagogy, assessment, and management. These three elements are interrelated in both function and implementation, and thus should be enacted in harmony.

\subsubsection{Pedagogy}

Pedagogy is an important component of an effective instructional core. Children's school readiness is positively correlated with high quality trained teachers and higher teacher class ratios (Reimers, 2020). Since teachers' professional development is still under resourced, we suggest reforming the training surrounding pedagogy in Vietnam. For the most successful TPD, teachers should share best practices and learn from each other both vertically and horizontally, in the form of professional learning communities. The higher the teacher training level and reputation, the lower the proportion of children who are vulnerable or at risk. Thus, there must be institutional, political, and professional support to make the necessary changes.

To support these changes, the psychological and cultural framework of teaching also needs to be shifted. We believe that through professional learning communities, teachers will be given safe spaces and opportunities to share and ask about their practice. These communities will empower teachers, by giving them more agency over their lessons. As teachers are the most important stakeholders of education reforms, strengthening the teaching force with strengthen the education system generally. Finally, since teachers' professional development is still under-resourced, we suggest reforming the training surrounding pedagogy. Here again, Vietnam could learn from OECD leaders such as Finland, Hong Kong, and Canada, which hold strict standards for training and selecting their teachers (Reimers, 2020).

\subsubsection{Assessment}

Vietnamese students at all levels are reportedly lacking in skills and motivation; according to the most recent ESA report, a non-negligible number of students 
report dislike for attending school or their poor learning capacities, as well as financial constraints (MOET, 2020). We believe that some degree of this pattern can be attributed to Vietnam's educational assessment system, which is still too heavily focused on results rather than processes, and further exacerbates the mismatch between education and practical market demands. With this in mind, we believe that the espoused goals and framework of Vietnam's education system should be changed. The objectives of education could be renovated to better fit the international standards of education, proposed by the OECD report. Rote learning should be abandoned and project-based learning, which suggests cooperation and innovation, should be emphasized more. In this case, we believe that cultural and psychological shifts (especially from parents and teachers) are important and will help to lead the Vietnamese education system towards accepting more formative assessments as opposed to summative assessments.

\subsubsection{Management}

Ultimately, the management of education (from the level of the Ministry of Education down to district level leaders or principals), the context of education (sociocultural environment, expectations, and norms), as well as the actual pedagogy of education must all come together cohesively to deliver results. Since no single part of this system can function without the other parts, spending on curriculum will amount to nothing without school leaders and teachers who can carry out the pedagogy. If the Vietnamese education system is to create successful training and policy for professional development, it will need continuous support from all institutional and political structures and key stakeholders. Empowering teachers and school leaders will be the most important effort in building on Resolution 29 into the future.

In addition, considering that decentralizing spending autonomy is proven to be ineffective in Vietnam, we suggest that Vietnam holds most of its budgetary power in the central educational authority. Compared with smaller or higher-income countries, Vietnam does not currently have the infrastructure to support breaking the federal budget on education regionally. We also recommend that Vietnam makes its spending more transparent; in countries like Finland, making educational costs publicly available has been proven to have positive results for public discourse and educational change (Reimers, 2020).

\subsection{Conclusions}

Education should be leveraged as an indispensable asset in confronting the many uncertainties that the future holds for Vietnam. Newly emerging challenges concern the quality of Vietnam's human resource base: the need for higher skill levels, foreign and Western languages, and IT competencies to function in an internationalized 
market and educational environment. In Vietnam's education policies since 2000, and especially with Resolution 29 in 2013, the dialogue around education has begun to reflect notions of a "learning society." This is a positive trend, which should be encouraged and supported.

Vietnam has been an emerging dragon in education for the last decade, in large part due to the ideologies and successes of Resolution 29. Moving forward, Vietnam can build on the strengths of Resolution 29, and tackle its limitations in the next round of reform. Vietnam has only more success yet to come. The dragon is only waking up.

\section{References}

CCCP (Central Committee of Communist Party). (2013). Resolution No. 29: Fundamental and comprehensive innovation in education.

CPTC (Central Propaganda and Training Commission). (2018). Report on 5-year implementation of resolution 29-NQ/TW, C.P.a.T. Commission.

Dang, H.-A.H., \& Glewwe, P. W. (2018). Well Begun, but aiming higher: A review of Vietnam's education trends in the past 20 years and emerging challenges. The Journal of Development Studies, 54(7), 1171-1195.

DIC (Department of International Cooperation). (2019a). Implementation report of decree 86 on cooperation and foreign investment in education, MOET.

DTA (Department of Teachers and Administrator). (2019). Annual report 2019, MOET.

Duggan, S. (2001). Educational reform in Vietnam: A process of change or continuity? Comparative Education, 37(2), 193-212.

Duong, T. (2020). Department of highschool education, department of primary education, renovation of general education project and textbook pricing, Retrieved from: https://giaoduc.net.vn/ giao-duc-24h/vu-giao-duc-trung-hoc-tieu-hoc-du-an-rgep-va-chuyen-gia-sach-giao-khoa-moipost208218.gd.

ESNP (Office of Educational Science National Program). (2020). Report on the implementation of the national educational science program 2016-2020, MOET.

ETEP (Enhancing Teacher Education Project). (2019). Evaluation report of the project to strengthen the capacity of key normal universities.

GSO (General Statistical Office). (2016). Education financing in Vietnam, 2009-2013.

GSO. (2017). National accounts, state budget and insurance, in statistical yearbook of Vietnam 2017, Statistical Publishing House.

Ha, V. (2020). Ministry of education and training asked for permission not to compile textbooks, Retrieved from: https://tuoitre.vn/bo-gd-dt-xin-khong-lam-sach-giao-khoa-202005162 25014388.htm.

Hoang, N. V. (2018). Examinations and education reform, Retrieved at: https://baoquocte.vn/thicu-va-doi-moi-giao-duc-77271.html.

Hoang, V. Q., et al. (2019), The status of educational sciences in Vietnam: A bibliometric analysis from Clarivate web of science database between 1991 and 2018, Problems of Education in the 21st Century (Vol. 78, No. 4, pp. 644-662).

IMF (International Monetary Fund). (2017). Vietnam: Selected issue, IMF Country report No. $17 / 191$.

Kataoka, S., Vinh, L. A., Kitchlu, S., \& Inoue, K. (2020). Vietnam's Human capital: Education success and future challenges, World Bank.

Le, M. H. (2020). Where Be the 'Magic Bullet' for educational change? Vietnam and the quest of policy borrowing from abroad. Journal of Educational Change, 21(3), 455-466. 
Ly, T. T., \& Marginson, S. (2019). Internationalisation in Vietnamese higher education. Springer.

McAleavy, T., Ha, T. T., \& Fitzpatrick, R. (2018). Promising practice: Government schools in Vietnam, Education Development Trust.

MOET (Ministry of Education and Training). (2018a). Report on education universalization.

MOET. (2018b). Circular 32/2018/TT-BGDĐT on the implementation of the national general education curriculum.

MOET. (2020). Educational sector analysis.

Nguyen, K. S., et al. (2020). Five-year implementation of resolution 29 on fundamental and comprehensive reform of education in Vietnam, National project-Final Report.

Reed, J. (2018). Education in Vietnam: Very good on paper, Retrieved from Financial Times: https:// www.ft.com/content/da4387d0-aba8-11e8-8253-48106866cd8a.

Reimers, F. (2020). Educating students to improve the world (pp. 1-22). Chapter 1. Five Eyes to Educate Global Citizens. The Need for a Useful Theory of Global Education.

Thanh, N. D., Patrinos, H., \& Thang, P. V. (2018). The economic case for education in Vietnam, World Bank.

UNICEF \& GSO. (2018). Children with disabilities in Vietnam.

Viet, N. V., et al. (2020). Solutions to improve the efficiency and effectiveness of State budget expenditure on education in Vietnam, National Project-Final report.

Vinh, L. A. (2019). Vietnam education from Doi Moi: From a revolutionary reform to ceaseless renovation, Background paper for World Bank Human Capital Project.

VNIES (Vietnam Institute of Educational Sciences). (2020). Evaluation of implementation of the 2011-2020 education development strategy, Final report.

VNIES (2017). Evaluation reports on implementations of circular 30 and circular 22 on primary student assessment.

VNIES (2021). Evaluation report on curriculum and textbook implementation for first grade students in the school year 2020-2021.

World Bank. (2016). Science, technology and innovation in Vietnam.

World Bank. (2019). Science, technology and innovation in Vietnam.

World Bank. (2020). Improving the performance of higher education in Vietnam: Strategic priorities and policy options, Higher Education Sector Report.

Anh Vinh Le is the Director General of Vietnam Institute of Educational Sciences (VNIES) and the Director of National Center for Sustainable Development of General Education Quality. Before joining VNIES, he held several positions at University of Education, Vietnam National University, including Dean of Faculty of Teacher Education, Director of Center for Educational Research and Applications, and Principal of High school of Educational Sciences. He has published more than 70 papers at international journals (both in Math and Education) and is leading a research group at Vietnam Institute of Educational Sciences on developing Vietnam Educational Strategy Framework 2021-2030. He got his Ph.D. in Mathematics at Harvard University in 2010 and came back to Harvard to get a Ed. M. in International Education Policy in 2021.

Puyuan Han is an education entrepreneur currently based in Shanghai, China. Puyuan has been a teacher since he was 19 years old and has managed to teach over 600 students. He also managed and founded several education companies which specialized in college applications and quality education. Puyuan earned an Ed.M Degree in Education Policy and Management from Harvard Graduate School of Education in 2021 and a B.A in International Relations and Quantitative Economics from Tufts University in 2018.

Maw Maw Khaing is an educator from Myanmar. She is the founder of New Education Ventures which provide quality education for Myanmar children. She leads Montessori preschools, K-12 
Bilingual Schools in Myanmar. Teaching children and training teachers to learn early literacy in both Myanmar and English has been the focus of her work in the past three years as she develops her venture. She has also worked with the Ministry of Education, Myanmar on the development of a public online university. She is a candidate for Ed.M. Degree from the Harvard Graduate School of Education in 2022.

Olivia Farrar is a researcher and writer currently based in Rochester, New York. Olivia earned a B.A. in English Literature from Harvard College in 2021 and will be pursuing her Master's in Museum Studies at Oxford University, Class of '23. Olivia has served on the U.S. National Team for rowing 4 times. She has an interest in education studies and policy reform, with both a domestic and international focus. Olivia was homeschooled growing up, which led to her interest in educational change.

Open Access This chapter is licensed under the terms of the Creative Commons Attribution 4.0 International License (http://creativecommons.org/licenses/by/4.0/), which permits use, sharing, adaptation, distribution and reproduction in any medium or format, as long as you give appropriate credit to the original author(s) and the source, provide a link to the Creative Commons license and indicate if changes were made.

The images or other third party material in this chapter are included in the chapter's Creative Commons license, unless indicated otherwise in a credit line to the material. If material is not included in the chapter's Creative Commons license and your intended use is not permitted by statutory regulation or exceeds the permitted use, you will need to obtain permission directly from the copyright holder. 